\title{
Fabrication, $\mathbf{N}$-doping Mechanism and Evaluation of $\mathbf{N}$-doped $\mathrm{TiO}_{2}$ Thin Films Based on Laser Ablation Method
}

\author{
S. Somekawa, Y. Kusumoto*, H. Yang, M. Abdulla-Al-Mamun, and B. Ahmmad \\ Department of Chemistry and Bioscience, Graduate School of Science and Engineering \\ Kagoshima University, 1-21-35 Korimoto, Kagoshima 890-065, Japan
}

Received 3 August 2009, accepted in a revised form 15 November 2009

\begin{abstract}
The relation among the change of the crystal structure, the amount of doped $\mathrm{N}$ and the photocatalytic activity for the decomposition of methylene blue was studied. The N-doping was promoted by the change of the crystal structure from the rutile phase to the anatase phase. The photocatalytic activity for the decomposition of methylene blue was enhanced by an increase in the amount of anatase crystals and doped $\mathrm{N}$.
\end{abstract}

Keywords: Laser ablation; N-doping process; Crystal change; $\mathrm{N}$-doped $\mathrm{TiO}_{2}$ thin film; Dye decomposition.

(C) 2010 JSR Publications. ISSN: 2070-0237 (Print); 2070-0245 (Online). All rights reserved.

DOI: 10.3329/jsr.v2i1.2992 J. Sci. Res. 2 (1), 17-23 (2010)

\section{Introduction}

The earth is faced with difficult problems such as global warming and energy resources. It is important to create renewable energy resources such as hydrogen instead of using fossil fuels. Environmental pollution, for example, dioxin contamination is also regarded as a serious global problem.

Titanium (IV) oxide $\left(\mathrm{TiO}_{2}\right)$ is well known as an efficient photocatalyst which can produce hydrogen and decompose pollutants [1-4] using light. However, it is only activated under UV light because of its wide band gap. Therefore, the fabrication of visible light-responsive photocatalysts has received considerable attention because visible light occupies the main part of solar light. The development of the future generation of photocatalytic materials is important for the efficient use of solar light. There have been many reports [5-26] on the introduction of $\mathrm{N}$ atoms through substitutional doping into the $\mathrm{TiO}_{2}$ lattice in place of $\mathrm{O}$ atoms, mainly to decrease the $\mathrm{TiO}_{2}$ band gap (3.2 eV) and hence

*Corresponding author: kusumoto@sci.kagoshima-u.ac.jp 
to improve the associated photocatalytic activity under visible light. Additionally, the state of doped nitrogen in the $\mathrm{N}$-doped $\mathrm{TiO}_{2}$ lattice was also discussed [27-29].

In 2004, Suda et al. [30, 31] reported the preparation of $\mathrm{N}$-doped $\mathrm{TiO}_{2}$ films from $\mathrm{TiN}$ and $\mathrm{TiO}_{2}$ by the laser ablation method under mixed gases of $\mathrm{N}_{2}$ and $\mathrm{O}_{2}$. However, they had no discussion on the $\mathrm{N}$-doping process and also no evaluation of the $\mathrm{N}$-doped $\mathrm{TiO}_{2}$ films. In this paper, we mainly studied the $\mathrm{N}$-doping process into $\mathrm{TiO}_{2}$ films by the laser ablation and the photocatalytic activity of the $\mathrm{N}$-doped $\mathrm{TiO}_{2}$ thin films.

\section{Experimental}

$5.5 \mathrm{~g}$ of $\mathrm{TiO}_{2}$ (Degussa P25) and $0.55 \mathrm{~g}$ of paraffin (Wako) were mixed to prevent cracking. It was pressed at $20 \mathrm{MPa}$ for $1 \mathrm{~h}$ and calcined at $400{ }^{\circ} \mathrm{C}$ for $6 \mathrm{~h}$ to form a $\mathrm{TiO}_{2}$ target. The second harmonics (532 nm) of a Nd:YAG pulse laser (Spectra-Physics Co., GCR-130-10) was used with a pulse width of $7 \mathrm{~ns}$ and a repetition rate of $10 \mathrm{~Hz}$. The laser beam of cross section $0.8 \mathrm{~cm}^{2}$ was focused onto an area of about $0.03 \mathrm{~cm}^{2}$ using a quartz lens with a focal distance of $30 \mathrm{~cm}$. To avoid the damage of the target by continuous irradiation of the laser beam, the target was rotated at $14 \mathrm{rpm}$ during the deposition.

Irradiation of the target with a laser beam melted the target to form a plume. The ablated-particles were accumulated on the quartz substrate and the $\mathrm{TiO}_{2}$ thin film was formed. The fluence of $2.8 \mathrm{~J} /\left(\right.$ pulse $\mathrm{cm}^{2}$ ) and the laser irradiation time of $12 \mathrm{~min}$ were used throughout the experiment. The distance between the substrate and the target was fixed at $3 \mathrm{~cm}$. The experiments were carried out under the following conditions; the substrate temperatures are 298-873 $\mathrm{K}$ and the nitrogen gas pressures are 3.3-267 Pa. The non-doped $\mathrm{TiO}_{2}$ thin film was also prepared as a reference by the laser ablation method under conditions of an $\mathrm{O}_{2}$ pressure of $133 \mathrm{~Pa}$ and a substrate temperature of 873 K.

The prepared thin films were characterized by XRD (X-ray diffraction, Rigaku Rint-2000) and XPS (X-ray photoelectron spectroscopy, Shimadzu ESCA-1000).

The photocatalytic activity of the prepared thin films was evaluated by measuring the rate of the decomposition of methylene blue under light irradiation. The thin film was fixed on a stand and dipped into a $50 \mathrm{~cm}^{3}$ beaker containing $1 \times 10^{-5} \mathrm{~mol} / \mathrm{dm}^{3}$ methylene blue solution. This solution was irradiated under visible light from the top of the beaker. A xenon lamp (Ushio, $500 \mathrm{~W}$ ) was used as a visible light source with an L42 cut-off filter. The rate of the decomposition of methylene blue was determined by measuring the change in the absorbance of methylene blue during irradiation using absorption spectroscopy (Shimadzu, MPS-2000).

\section{Results and Discussion}

Fig. 1 shows the absorption spectra of (a) the $\mathrm{TiO}_{2}$ thin film prepared at $600{ }^{\circ} \mathrm{C}$ under $\mathrm{O}_{2}$ gas of $133.3 \mathrm{~Pa}(1 \mathrm{Torr})$ and (b) the yellowish $\mathrm{N}$-doped $\mathrm{TiO}_{2}$ thin film prepared at $600{ }^{\circ} \mathrm{C}$ under $\mathrm{N}_{2}$ gas of $133.3 \mathrm{~Pa}$ (1 Torr). The nitrogen substitutional doping of $\mathrm{TiO}_{2}$ is thought to be a method for narrowing the band gap by changing the valence band structure without any change in the position of conduction band [14]. 


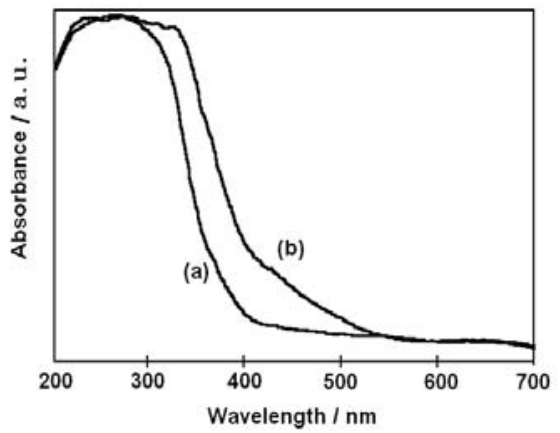

Fig. 1. Absorption spectra of (a) the white thin film and (b) the yellowish thin film under conditions of (a) $\mathrm{O}_{2} 133.3 \mathrm{~Pa}$ (1 Torr) and (b) $\mathrm{N}_{2} 133.3 \mathrm{~Pa}$ (1 Torr) (substrate temperature: $600{ }^{\circ} \mathrm{C}$ ).

XRD spectra of the $\mathrm{N}$-doped thin films indicate a decrease in the anatase phase with decreasing $\mathrm{N}_{2}$ gas pressure as shown in Fig. 2. The intensity in the rutile phase in turn increases with decreasing $\mathrm{N}_{2}$ gas pressure.

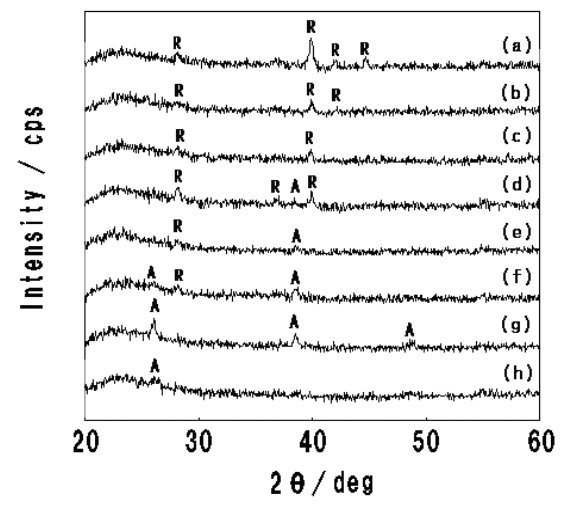

Fig. 2. XRD patterns of the thin films prepared under various nitrogen pressures ((a) $3.3 \mathrm{~Pa}$, (b) 6.7 $\mathrm{Pa}$, (c) $13 \mathrm{~Pa}$, (d) $27 \mathrm{~Pa}$, (e) $67 \mathrm{~Pa}$, (f) $133 \mathrm{~Pa}$, (g) $200 \mathrm{~Pa}$, (h) $267 \mathrm{~Pa}$ ). A and R denote anatase phase and rutile phase, respectively.

Fig. 3 shows the relation among the relative amount of doped $\mathrm{N}$ and the sum of the integrated intensity of all anatase peaks and that of rutile peaks as a function of $\mathrm{N}_{2}$ gas pressure at a substrate temperature of $873 \mathrm{~K}$. The rutile phase decreased, while the anatase phase appeared around $20 \mathrm{~Pa}$ and then increased with increasing $\mathrm{N}_{2}$-gas pressure. Kitazawa et al. [32] reported the effect of $\mathrm{O}_{2}$ gas pressure on the production of the rutile and the anatase using the laser ablation method. It can be explained as follows. The clustering of the ablated particles occurs during flight and then the crystal growth is induced on a heated substrate. With increasing gas pressure, the clustering of the laser-ablated particles progresses and their velocity decreases, resulting in the prevention of the crystal growth of the rutile and promotion of the anatase due to lack of the thermal 
energy. Such an explanation can be adopted also in our case of $\mathrm{N}_{2}$ gas atmosphere. The relative amount of anatase calculated using $\mathrm{AA} /(\mathrm{AA}+\mathrm{AR})$ (AA and $\mathrm{AR}$ are the total area of all anatase and rutile peaks, respectively) at an $\mathrm{N}_{2}$-gas pressure of $133 \mathrm{~Pa}$ (99\%) was higher than that of an $\mathrm{O}_{2}$-gas pressure of $133 \mathrm{~Pa}(80 \%)$ at a substrate temperature of 873 K.

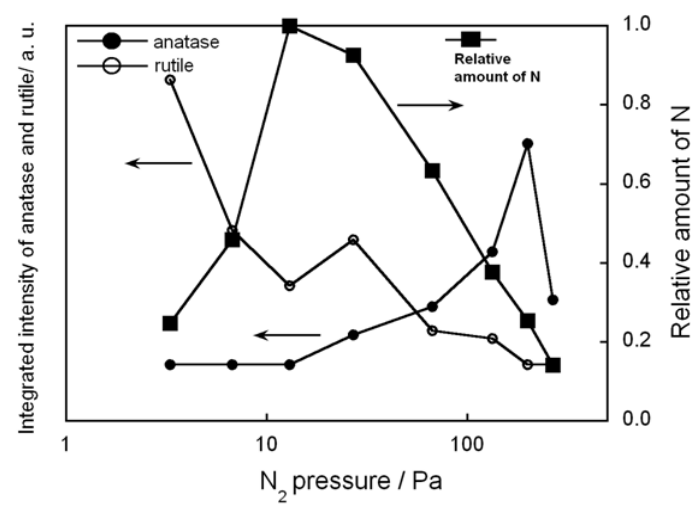

Fig. 3. The relation among the relative amount of doped $\mathrm{N}$, the integrated intensity of all anatase peaks and that of rutile peaks as a function of $\mathrm{N}_{2}$ gas pressure at a substrate temperature of $873 \mathrm{~K}$.

The relative amount of doped $\mathrm{N}$ was estimated from the XPS data using the ratio A / $A_{\max }$, where $A$ is the integrated intensity of the XPS peaks of nitrogen doped in the $\mathrm{TiO}_{2}$ lattices (the binding energy is ca. $397 \mathrm{eV}$ ) [30] and $A_{\max }$ is the maximum peak intensity of nitrogen under an $\mathrm{N}_{2}$ gas-pressure of $13 \mathrm{~Pa}$. The peaks around $406 \mathrm{eV}$ of the binding energy correspond to nitrogen species in air [30], which are adsorbed on the $\mathrm{TiO}_{2}$ surface and was almost constant at each $\mathrm{N}_{2}$ gas pressure. It is found from Fig. 1 that the amount of doped $\mathrm{N}$ increases with increasing $\mathrm{N}_{2}$-gas pressure up to around $20 \mathrm{~Pa}$ and decreases through the maximum. Notice that the pressure at which the formation of anatase phase starts corresponds to the maximum amount of doped $\mathrm{N}$. It is clear that the N-doping easily occurs near the pressure at which the change of the crystal structure from the rutile to the anatase starts because of its instability. The films turned yellow only when the substrate temperature was higher than $773 \mathrm{~K}$ and the yellow of the films became deeper at higher temperatures. These results imply that the $\mathrm{N}$-doping is accelerated by the thermal energy of the heated substrate. We suggest the $\mathrm{N}$-doping process as follows. (I) $\mathrm{N}_{2}$ molecules are adsorbed on the ablated $\mathrm{TiO}_{2}$ particles (plume) in the gas phase during flight (some nitrogen in the gas are doped into the $\mathrm{TiO}_{2}$ lattice, but it is not major), (II) the particles collide on the heated substrate, (III) the migration of the particles occurs on the heated substrate and (IV) nitrogen species are doped into the $\mathrm{TiO}_{2}$ lattice at the same time as the migration.

Fig.4 shows the SEM image of the $\mathrm{N}$-doped $\mathrm{TiO}_{2}$ thin film prepared by the laser ablation method $\left(\mathrm{N}_{2} 1 \mathrm{Torr}, 600^{\circ} \mathrm{C}\right)$. From this image, we can see that the surface is rough. A large number of pores were also observed. 


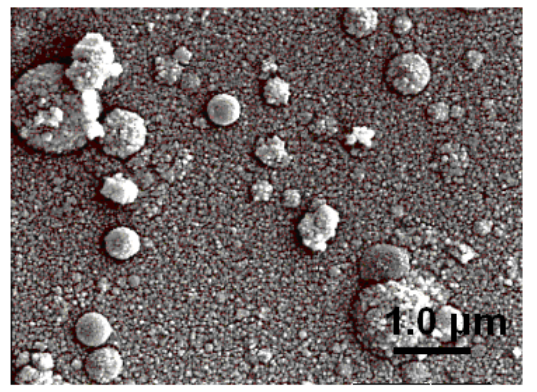

Fig. 4. The SEM image of the $\mathrm{N}$-doped $\mathrm{TiO}_{2}$ thin film $\left(\mathrm{N}_{2}: 133.8 \mathrm{~Pa}\right.$ (1 Torr), substrate temperature: $\left.600^{\circ} \mathrm{C}\right)$.

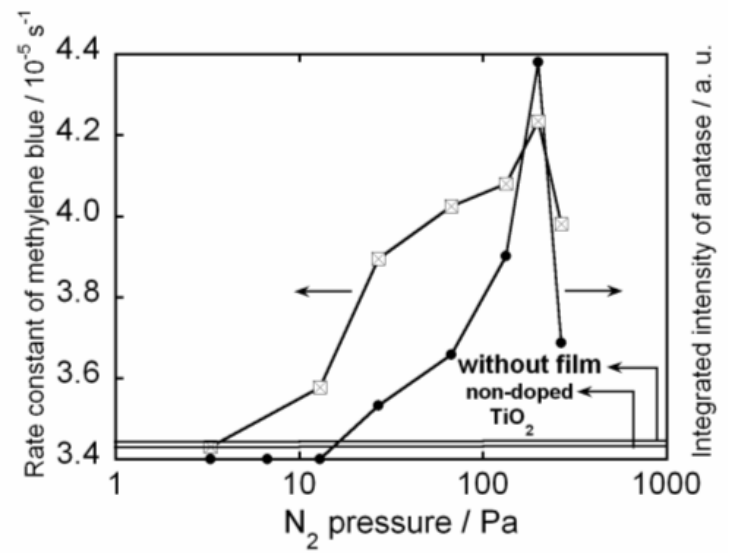

Fig. 5. The relation between the integrated intensities of all anatase peaks and the rate constant of the decomposition of methylene blue as a function of $\mathrm{N}_{2}$ gas-pressure at substrate temperature of $873 \mathrm{~K}$.

Fig. 5 shows the relation between the integrated intensities of all anatase peaks and the rate constant of the decomposition of methylene blue as a function of $\mathrm{N}_{2}$-gas pressure. The rate constant $k$ for the pseudo first order reaction was obtained from the initial linear portion using the relation (Eq. 1).

$$
\ln \left([M B] /[M B]_{0}\right)=-k t,
$$

where $[M B]_{0}$ is the initial concentration of methylene blue, $[M B]$ is the concentration of methylene blue after time $t$ of photocatalytic decomposition. An increase in the rate of methylene blue decomposition can be noticed in the pressure range of 3.3-200 $\mathrm{Pa}$ and the rate was decreased at $267 \mathrm{~Pa}$ as shown in Fig. 2. These increase and decrease are explained by the increase and decrease of the amount of anatase phase, respectively. Moreover, the curve of the rate constant was convex upword at the region of 150-200 Pa as compared with that of the amount of the anatase phase. This difference implies that the 
photocatalytic activity under visible light was enhanced by the increase of the amount of $\mathrm{N}$ doped in the $\mathrm{TiO}_{2}$ lattice.

\section{Conclusion}

In the present work, the $\mathrm{N}$-doped $\mathrm{TiO}_{2}$ thin films were fabricated by the laser ablation method and evaluated as a photocatalyst. We proposed the plausible mechanism of nitrogen doping by the laser ablation method. The elucidation of the mechanism will contribute to the development of more useful visible light-responsive photocatalyst thin films.

\section{Acknowledgements}

The present work was partly supported by Grant-in-Aid for Scientific Research (B) (No. 19360367) from Japan Society for the Promotion of Science (JSPS).

\section{References}

1. A. Fujishima, K. Honda, Nature 238, 37 (1972). doi:10.1038/238037a0

2. A. Yamakata, T. Ishibashi, H. Onishi, J. Mol. Catal. A: Chem. 199, 85 (2003). doi:10.1016/S1381-1169(03)00021-9

3. R. Pelton, X. Geng, M. Brook, Adv. Colloid Interface Sci. 127, 43 (2006). doi:10.1016/j.cis.2006.08.002

4. M. Ni, M. K. H. Leung, D. Y. C. Leung, K. Sumathy, Renew. Sust. Energ. Rev. 11, 401 (2007). doi:10.1016/j.rser.2005.01.009

5. R. Asahi, T. Morikawa, T. Ohwaki, K. Aoki, Y. Taga, Science 293, 269 (2001). doi:10.1126/science.1061051

6. R. Nakamura, T. Tanaka, Y. Nakato, J. Phys. Chem. B 108, 10617 (2004). doi:10.1021/jp048112q

7. Y. Wanga, D.J. Dorenb, Solid State Commun. 136, 186 (2005). doi:10.1016/j.ssc.2005.05.042

8. A. R. Gandhe, S. P. Naik, J. B. Fernandes, Microporous Mesoporous Mater. 87, 103 (2005). doi:10.1016/j.micromeso.2005.07.017

9. K. Kobayakawa, Y. Murakami, Y. Sato, J. Photochem. Photobiol. A: Chem. 170, 177 (2005). doi:10.1016/j.jphotochem.2004.07.010

10. C. D. Valentin, G. Pacchioni, A. Selloni, S. Livraghi, E. Giamello, J. Phys. Chem. B 109, 11414 (2005). doi:10.1021/jp051756t

11. S. Chu, S. Inoue, K. Wada, D. Li, J. Suzuki, Langmuir 21, 8035 (2005). doi:10.1021/la050902j

12. J. Yuan, M. Chen, J. Shi, W. Shangguan, Int. J. Hydrogen Energy 31, 1326 (2006). doi:10.1016/j.ijhydene.2005.11.016

13. K. Yang, Y. Dai, B. Huang, S. Han, J. Phys. Chem. B 110, 24011 (2006). doi:10.1021/jp0651135

14. H. Fu, L. Zhang, S. Zhang, Y. Zhu, J. Phys. Chem. B 110, 3061 (2006). doi:10.1021/jp055279q

15. K. Yamada, H. Nakamura, S. Matsushima, H. Yamane, T. Haishi, K. Ohira, K. C. R. Kumada, Comp. Rend. Chimie 9, 788 (2006). doi:10.1016/j.crci.2005.05.016

16. P. Xu, L. Mi, P. Wang, J. Cryst. Growth 289, 433 (2006). doi:10.1016/j.jcrysgro.2005.11.099

17. Y. Wang, C. Feng, Z. Jin, J. Zhang, J. Yang, S. Zhang, J. Mol. Catal. A: Chem. 260, 1 (2006). doi:10.1016/j.molcata.2006.06.044

18. K. Yang, Y. Dai, B. Huang, J. Phys. Chem. C 111, 12086 (2007). doi:10.1021/jp067491f

19. L. K. Randeniya, A. Bendavid, P. J. Martin, E. W. Preston, J. Phys. Chem. C 111, 18334 (2007). doi:10.1021/jp075938u

20. E. A. Reyes-Garcia, Y. Sun, K. Reyes-Gil, D. Raftery, J. Phys. Chem. C 111, 2738 (2007). doi:10.1021/jp0652289 
21. S. A. Chambers, S. H. Cheung, V. Shutthanandan, S. Thevuthasan, M.K. Bowman, A. G. Joly, Chem. Phys. 339, 27 (2007). doi:10.1016/j.chemphys.2007.04.024

22. M. Sathish, B. Viswanathan, R. P. Viswanath, Appl. Catal. B 74, 307 (2007). doi:10.1016/j.apcatb.2007.03.003

23. C. D. Valentin, E. Finazzi, G. Pacchioni, A. Selloni, S. M. C. Livraghi, P. E. Giamello, Chem. Phys. 339, 44 (2007). doi:10.1016/j.chemphys.2007.07.020

24. L. Wan, J. F. Li, J.Y. Feng, W. Sun, Z. Q. Mao, Appl. Surf. Sci. 253, 4764 (2007). doi:10.1016/j.apsusc.2006.10.047

25. Y. Nakano, T. Morikawa, T. Ohwaki, Y. Taga, Chem. Phys. 339, 20 (2007). doi:10.1016/j.chemphys.2007.05.031

26. X. Chen, X. Wang, Y. Hou, J. Huang, L. Wu, X. Fu, J. Catal. 255, 59 (2008). doi:10.1016/j.jcat.2008.01.025

27. X. Chen, C. Burda, J. Phys. Chem. B 108, 15446 (2004). doi:10.1021/jp0469160

28. M. Sathish, B. Viswanathan, R. P. Viswanath, C. S. Gopinath, Chem. Mater. 17, 6349 (2005). doi: $10.1021 / \mathrm{cm} 052047 \mathrm{v}$

29. C. S. Gopinath, J. Phys. Chem. B 110, 7079 (2006). doi:10.1021/jp054495w

30. Y. Suda, H. Kawasaki, T. Ueda, T. Ohshima, Thin Solid Films 453, 162 (2004). doi:10.1016/j.tsf.2003.11.185

31. Y. Suda, H. Kawasaki, T. Ueda, T. Ohshima, Thin Solid Films 475, 337 (2005). doi:10.1016/j.tsf.2004.07.047

32. S. Kitazawa, Y. Choi, S. Yamamoto, T. Yamaki, Thin Solid Films 515, 1901 (2006). doi:10.1016/j.tsf.2006.07.032 